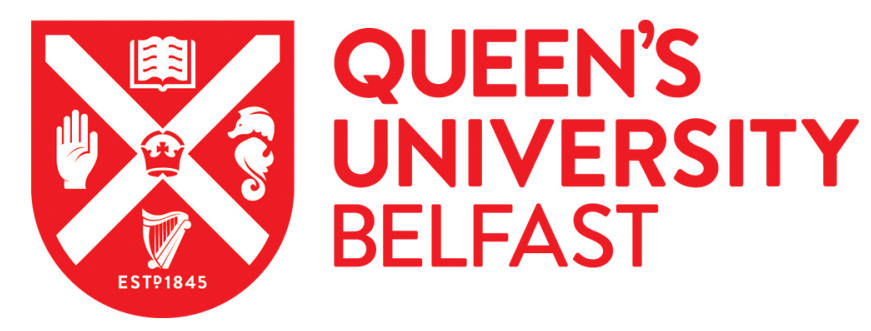

\title{
Patient anxiety and IV sedation in Northern Ireland
}

Hunt, O., McCurley, N., Dempster, M., \& Marley, J. (2012). Patient anxiety and IV sedation in Northern Ireland. British Dental Journal, 210(12), 575-579. https://doi.org/10.1038/sj.bdj.2011.483

\author{
Published in: \\ British Dental Journal
}

Document Version:

Early version, also known as pre-print

Queen's University Belfast - Research Portal:

Link to publication record in Queen's University Belfast Research Portal

\section{Publisher rights}

(c) 2011 Macmillan Publishers Limited. This work is made available online in accordance with the publisher's policies. Please refer to any applicable terms of use of the publisher.

\section{General rights}

Copyright for the publications made accessible via the Queen's University Belfast Research Portal is retained by the author(s) and / or other copyright owners and it is a condition of accessing these publications that users recognise and abide by the legal requirements associated with these rights.

Take down policy

The Research Portal is Queen's institutional repository that provides access to Queen's research output. Every effort has been made to ensure that content in the Research Portal does not infringe any person's rights, or applicable UK laws. If you discover content in the Research Portal that you believe breaches copyright or violates any law, please contact openaccess@qub.ac.uk. 


\section{Patient anxiety and IV sedation in Northern Ireland}

Orlagh Hunt ${ }^{1}$, Nicola McCurley ${ }^{2}$, Martin Dempster $^{3}$ and John Marley ${ }^{4}$

${ }^{1}$ Dr Orlagh Hunt, Lecturer, Centre for Dental Education, School of Medicine, Dentistry and Biomedical Sciences, Queen's University Belfast, Grosvenor Road, Belfast BT12 6BP

${ }^{2}$ Ms Nicola McCurley, Specialty Doctor in Oral Surgery, The Ulster Hospital, Upper Newtownards Road, Belfast BT16 1RH

${ }^{3}$ Dr Martin Dempster, Research Co-ordinator, DClinPsych Programme, School of Psychology, Queen's University Belfast, University Road, Belfast BT7 1NN

${ }^{4}$ Dr John Marley, Senior Lecturer/ Consultant in Oral Surgery, Centre for Dental Education, School of Medicine, Dentistry and Biomedical Sciences, Queen's University Belfast, Grosvenor Road, Belfast BT12 6BP 


\begin{abstract}
In recent years there has been an increase in the provision of conscious sedation, which is said to be a safe and effective means of managing the anxious patient. However, there are no guidelines to aid the dental practitioner in assessing the patient's need for sedation based on their level of anxiety. The present study investigated the importance of patient anxiety as an indicator for sedation. Using focus groups to inform the development of narrative vignettes, ninety-nine practitioners responded to a series of scenarios to determine whether the level of patient anxiety and the patient's demand for IV sedation influenced their decision- making.

Level of dental anxiety had a stronger influence on the clinician's decision-making than patient demand, with increasing levels of dental anxiety being positively associated with the likelihood of clinicians indicating a need for IV patient sedation and also, the likelihood of clinicians providing IV sedation to these patients. Only $14 \%(\mathrm{n}=14)$ of respondents reported formally assessing dental anxiety.
\end{abstract}

While dental anxiety is considered to be a key factor in determining the need for IV sedation, there is a lack of guidance regarding the assessment of anxiety among patients. 


\section{Introduction}

Anxiety is quoted by many patients as a barrier to the receipt of dental care ${ }^{(1,2,3,4)}$. It is said to be one of the most important and challenging aspects of everyday clinical dental practice $^{(5)}$. Indeed in the Adult Dental Health Survey, up to $45 \%$ of people cited fear of dentistry as a major barrier to the receipt of dental care ${ }^{(6)}$. Recent studies have also demonstrated that the incidence of dental fear does not appear to be decreasing despite the advances in dentistry and dental treatment ${ }^{(7)}$. Whilst various instruments are available to assess anxiety ${ }^{(8,9,10)}$ and have been designed for specific dental situations ${ }^{(11)}$ there is little data available in relation to their routine application in the dental setting.

Dental anxiety is often cited as an indication for the provision of IV sedation. Much information is available to the clinician on the appropriate practice, safety aspects and correct equipment requirements for the practice of conscious IV sedation ${ }^{(12,13,14)}$ yet none of these guidelines state how dental anxiety should be assessed or what level of anxiety is necessary to indicate the need for IV sedation.

Conscious sedation is a pharmacologically-induced state of relaxation in which the patient remains conscious and cooperative throughout the dental treatment. The procedure allows the patient to maintain their protective reflexes and vital signs. The patient should also remain able to respond rationally to command during any treatment ${ }^{(15,16,17)}$. Conscious sedation is therefore a valid and valuable treatment option but it is not without risk. It is important that the indications for its use are evidence-based. In addition, in an environment of increasing cost restriction it 
would be reasonable to argue that its indications for use should be carefully considered.

The publication in July 2000 of 'A Conscious Decision' by an expert group chaired by the Chief Medical and Dental Officers ${ }^{(15)}$ expressed concern over safety and standards in the provision of Dental General Anaesthesia within the profession and consequently resulted in its practice being restricted to the hospital environment. The Working Party publication 'Standards for Conscious Sedation in Dentistry' (12) and the General Dental Council (GDC) ${ }^{(18)}$ have stated that the control of anxiety and pain is fundamental to the practice of dentistry. Taken together with the public demand for a method of treatment, which allowed wakefulness, but insensibility to pain and amnesia, there has been a rise in the use and demand for conscious sedation.

Furthermore, whilst recent surveys in the UK have highlighted that conscious sedation is becoming a very popular management option ${ }^{(7,19)}$ it is still not being practiced by all practitioners, with many not feeling equipped to provide it. A survey of General Dental Practitioners in Northern Ireland in $2005^{(20)}$ found up to $43 \%$ of respondents did not provide sedation for their own patients but preferred to refer patients for such treatment options. This study also investigated referral patterns for sedation demonstrating that $39 \%$ of respondents would or have referred patients who require sedation to another high street practitioner, $35 \%$ would or have referred to the Community Dental Service and $26 \%$ would or have referred patients to the Hospital setting for sedation. Only $53 \%$ of respondents felt adequate sedation 
services were available in their area. Seventy-three per cent of respondents felt further training in sedation would be advantageous.

A similar study in Scotland ${ }^{(1)}$ found that $75 \%$ of practitioners felt there was a real need for sedation in their daily practice however, less than 50\% felt able to offer this option to their own patient. In the same survey $70 \%$ of those questioned felt there was a need for further training in the area of sedation. This information would suggest there is a training need in the practice of IV sedation but there may be other influences on IV sedation practice which have not been explored in these studies.

The primary aim of the present study was to explore the importance of patient anxiety as an indicator for the provision of IV sedation among dental practitioners in Northern Ireland

Ethical approval for the study was obtained from Queen's University Belfast (PREC 11-09).

\section{Method}

\section{Focus groups}

A series of focus groups were organised to gain a better understanding of the issues surrounding the treatment of dental patients using sedation. Four focus groups were organised for various dentally qualified professionals: General Dental Practitioners $(n=4)$, Specialist practitioners in Oral Surgery $(n=5)$, Community Dental Officers 
$(n=4)$ and Consultants in Oral and Maxillofacial Surgery $(n=3)$. The focus groups were audio-recorded with the permission of each group and moderated by a health psychologist and one of the dentally qualified investigators. Participants in the focus groups also completed a questionnaire relating to demographic issues, undergraduate and postgraduate training and their current practice of IV sedation. The information obtained from the focus groups was used to inform the design of a series of narrative vignettes which were then used to assess the factors which influence dental practitioners in choosing to provide IV sedation.

\section{Vignettes}

A number of key themes emerged from the focus groups with the two main issues identified as:
a. the patient's demand for sedation
b. the practitioner's assessment of the patient's level of anxiety.

Six vignettes were then developed, each describing a scenario involving a patient who required the removal of a number of teeth. The treatment description remained as a constant in each of the vignettes. To reflect the findings from the focus groups, each vignette portrayed a different level of patient anxiety and a statement on the patient's level of demand for sedation. The vignettes were designed to provide all possible permutations of levels of anxiety and demand for treatment (Appendix A).

Participants were asked to answer two questions in relation to each vignette: 
1. How likely do you think it is that the patient needs sedation?

2. How likely are you to provide this patient with sedation?

Responses to each question were made on a five point scale with 1 being 'very likely' and 5 being 'not at all likely'.

\section{Demographic Questionnaire}

All of the participants were asked to complete a modified version of the focus group questionnaire to obtain information about their current practice of IV sedation. Additional questions were asked to address whether participants formally assessed anxiety and, if so, how this was assessed. Participants were also given a list of possible influencing factors when deciding to offer sedation to a patient and asked to rank order the influence of these factors on their decision-making (Appendix B).

\section{Web-based study}

Every dentist in Northern Ireland who was registered on the General Dental Council's list was eligible for inclusion in the study. An invitation asking dentists to take part was issued by post. Details of the study were included in each dentist's schedule of payment with information provided about how to take part online. An online site was piloted by a selected group from the original focus groups and a number of hospital dentists to determine ease of comprehension and navigation of the site.

The vignettes and questionnaire were made available to a potential audience of 700 GDPs, 20 Community Dental Officers, 10 Specialist Practitioners in Oral Surgery 
and 10 Consultants in Oral and Maxillofacial Surgery. The website remained active for a period of 20 weeks. During that time two further reminders about the study were sent by post to all potential participants. Email reminders were sent where possible and a further reminder was made about the study at 2 consecutive local GDP meetings.

The data were entered into SPSS, Version 15, for Statistical Analysis.

\section{Results}

Completed responses were received from 99 clinicians (13\%), 58\% of whom were male. The median age group was $30-40$ years (25\% aged $23-30$ years; $35 \%$ aged $31-$ 40 years; $29 \%$ aged $41-50$ years; and $11 \%$ aged over 51 years). The majority of respondents had graduated after 1980 (10\% had graduated between $1961-1980 ; 32 \%$ graduated 1981-1990; 36\% graduated 1991-2000; 22\% graduated from 2001 onwards).

A breakdown of the sector of work of the clinicians shows that $78 \%$ of respondents were GDP's, $7 \%$ were community dental officers, $5 \%$ were specialist practitioners and $10 \%$ were hospital-based Consultants in Oral and Maxillofacial Surgery.

Regarding relevant postgraduate training in IV sedation, 45\% (45/99) of respondents had attended a Northern Ireland Medical \& Dental Training Agency (NIMDTA) recognised course, most of which were within the past 5 years. Twenty three per cent of the clinicians stated that they currently perform IV sedation. 
Analysis of the responses to the vignettes (using a $3 \times 2$ ANOVA) indicated that clinicians were more likely to respond that the patient should be given sedation with increasing levels of patient anxiety $(\mathrm{F}(2,196)=75.514, \mathrm{p}<0.001)$. A statistically significant difference was also observed between the vignettes indicating a high and low demand for sedation. Clinicians reported that the patients who demanded sedation in the vignettes were more likely to need sedation than the patients who did not demand sedation in the vignettes $(\mathrm{F}(1,98)=27.443, \mathrm{p}<.001)$.

However, there was no statistically significant interaction between level of anxiety and level of demand with regard to the clinicians' perceptions of the need for sedation $(\mathrm{F}(2,196)=2.244, \mathrm{p}=0.114)$.

Conclusions about these relationships were not affected by the inclusion of age, gender and graduation year as covariates in the analysis. The mean scores are provided in Table 1 and suggest that anxiety has a stronger impact on the decision about sedation than demand.

Clinicians were also provided with a list of factors that the focus group research concluded may be important considerations in clinicians' decision-making about sedation. Clinicians ranked these factors in terms of importance in their decision about the need for sedation for a patient. The factor ranked as most important was anxiety followed by medical history (Table 2). 
Fourteen percent (14\%) of the respondents said they assess anxiety formally, with only two respondents using a formally validated anxiety questionnaire. The other respondents used either personal experience or un-validated questionnaires to determine the level of anxiety of their patients.

\section{Discussion}

The aim of this study was to explore the importance of patient anxiety as an indicator for the provision of IV sedation among dental practitioners in Northern Ireland. Forty-nine per cent of respondents reported offering sedation to their patients. However, only twenty three per cent $(n=23)$ of the clinicians taking part in the study stated that they currently perform IV sedation. Only $14 \%(\mathrm{n}=14)$ formally assess anxiety, with only two clinicians reporting the use of a validated questionnaire to do so.

Responses to the vignettes indicate that clinicians were more likely to respond that the patient should be given sedation with increasing levels of patient anxiety, making sedation more likely to be prescribed as the patient displayed more anxiety. When asked to rate a number of factors that may be important in decision-making about IV sedation, clinicians ranked anxiety as the most important factor. While clinicians believe that anxiety is the most important factor to consider when deciding on the administration of IV sedation, it is concerning to see that only $14 \%$ of those asked reported that they assess anxiety in a formal way.

It is possible, that in practice, anxiety is assessed more informally than the clinician realises and that there is a heavy reliance on subjective elements such as intuition or past anecdotal experience. The possibility with this type of informal assessment is 
that a clinician may provide a patient with sedation who is not necessarily in true need of it or alternatively they may deny someone the benefit of sedation where it is required. At present there does not appear to be any specific standard guidelines available to dental professionals in terms of assessment of anxiety and therefore it is understandable that they would determine the need for sedation in the way that they currently do. A difficulty arises however if the clinician incorrectly assesses the patient's need for sedation based on personal intuition. A negative experience of dental treatment could result in the patient experiencing even greater anxiety and prove detrimental to future attendance and/or treatment with their dentist.

The lack of use of standardised and robust measurements for anxiety places a heavy onus on both the patient to appropriately request sedation and on the clinician to correctly decide that it is needed. Further research warrants a detailed examination of the way in which clinicians currently assess anxiety, and also their knowledge of the various methods available to do so.

Furthermore from the vignettes, it emerged that dentists were more likely to rate a patient to be in need of sedation where the patient demanded sedation. This is an interesting finding which suggests that the patient's expectation for sedation may influence the clinician's decision to administer it. It is possible that the patient is able to correctly assess their own need for sedation for various dental procedures and the dentist is then in agreement with this request. However, a recent study has demonstrated that $38 \%$ of patients did not know sedation was available for dental treatment and therefore such patients do not have the ability to request sedation ${ }^{(7)}$. It is also possible that the patient is basing their request for sedation on factors which may not necessarily be good indicators for sedation such as a lack of knowledge 
about the treatment or having received previous treatment under sedation. While it is important to take the patient's requests on board and explore their reasons for such requests it is also imperative that the dentist uses sound clinical evidence to support any decision for administration of or referral for sedation. At the same time it is important that the dentist listens to the patient in terms of their fears and anxieties surrounding treatment. Patient involvement in his/her own treatment options is recognised as an important factor in promoting well-being. Therefore, it is essential that the dentist is willing to listen to the patient's concerns and beliefs surrounding their treatment and care. An open dialogue between the dentist and the patient, where both parties are content with the final treatment decision, will lead to greater satisfaction for both the patient and dentist.

It is interesting to note that while demand for sedation was a strong influencing factor when the dentists were discussing sedation in the focus groups, it was rated as less important than a number of other factors in the rank-order of items that might influence decision-making. It is possible that dentists know that demand for sedation by the patient is not a sound clinical indicator for sedation and therefore they did not rate it highly in the rank order of items presented. However, it seems that in reality it does play some part in their decision making as evidenced during the focus group discussions and their responses to the vignettes. Perhaps the clinicians felt more comfortable indicating a need for sedation when demand was high as presented in the vignettes and also while discussing it in the relaxed atmosphere of the focus groups. 
Demand for sedation was rated as having less influence on decision-making than the patient's medical history, availability of a chaperone, and the clinician's own training experience when using a rank-order of items. While these other issues were not key factors that emerged during the focus group discussions, and therefore did not form part of the vignettes, it would seem that the dental professional has a wide range of factors to consider when deciding on IV sedation as a patient management option. Vignettes incorporating a fuller picture of the patient could be used in future work in this area. However, this does demonstrate the multiple and interacting factors which are likely to be at play when the dental health professional is making a decision about IV sedation.

Age, gender and year of graduation did not affect results suggesting that having greater experience was not a factor in the decision making process. This seems to provide further evidence that the use of sedation is based on intuition or some other related subjective factor.

\section{Use of focus groups and vignettes}

Vignettes provide a valuable technique for exploring people's perceptions, beliefs and meanings about specific situations, and are especially useful for sensitive areas of inquiry that may not be readily assessable through other means. ${ }^{(21)}$ The technique is gaining widespread use in healthcare. ${ }^{(22)}$ As there was very little previous research on how clinicians assess a patient's need for sedation based on their anxiety the authors felt that the use of focus groups and the subsequent vignettes were the best way to identify the main issues relating to sedation and anxiety as well as 
providing the clinician with a contextualised situation in which they could provide their opinion.

\section{Response rate}

The focus groups were organised to represent all possible clinicians who would be referring or providing sedation to patients and therefore were considered to be representative of the population under study. A web based approach to data collection in the main study was chosen as it allowed full access to the large number of participants who were eligible for inclusion. While web-based studies can have a poor response rate it was felt that this was the most appropriate method of data collection to optimise the response rate among busy dental health professionals. The response rate in this study reflects the fact that all dentally qualified professionals in Northern Ireland were included in the study (99 out of a possible 740 participants). Future research in this area could build upon the findings of the present study but use a more clearly defined sample to enhance the response rate. Ideally it would have been preferable had more clinicians taken part in the web based study. However, these findings do give us a previously unknown insight into the factors at play when dental professionals consider sedation for their patients.

\section{Conclusions}

1. Anxiety is considered by dental health professionals to be the most important factor when assessing a patient's need for IV sedation

2. Anxiety is infrequently assessed in a formal manner. 


\section{References}

1. Foley J. The way forward for dental sedation and primary care? British Dental Journal. 2000;193(3):161-164.

2. Leitch JA, Girdler NM. A survey of the teaching of conscious sedation in dental schools of the UK and Ireland. British Dental Journal. 2000;188(4):211-216.

3. Morgan CL, Skelly AM. Conscious sedation services provided in secondary care for restorative dentistry in the UK: A survey. British Dental Journal. 2005;198:631-635.

4. Silegy T, Kingston RS. An overview of outpatient sedation and general anaesthesia for dental care in California. Journal of the California Dental Association. 2003;3(5):405-412.

5. Craig DC and Skelly AM. Dentistry and Anaesthesia. British Dental Journal. 1994;176(3):88.

6. Kelly M et al. Adult Dental Health Survey: Oral health in the United Kingdom 1998. Government Statistical Service.

7. Allen EM, Girdler NM. Attitudes to Conscious Sedation in patients attending an Emergency Dental Clinic. Primary Dental Care. 2005;12(1):27-32. 8. Bjelland I et al. The validity of the Hospital Anxiety and Depression Scale an updated literature review. Journal PSychosom Res. 2002;52(2):69-77.

9. Lowe P. Psychomotor Analyses of the Adult Manifest Anxiety Scale- Adult Version among young and meddle aged adults. Educational and Psychological Measurement. 2004;64(4):661-681.

10. Lovibond PF, Lovibond SH. The structure of negative emotional states: Comparison of the Depression Anxiety Stress Scales (DASS) with the Beck Depression and Anxiety Inventory. Behav Res Ther. 1995;33(3):335-343. 
11. Fung DE et al. Pain reported by children after dental extractions under general anaesthetic. A pilot study. Int J of Paed Dent. 1993;3(1):23-28.

12. Dental Sedation Teachers Group. Standards for Conscious Sedation in Dentistry. October 2000.

13. Standards for Dental Professionals. General Dental Council. www.gdcuk.org May 2005.

14. UK Academy of Medical Royal Colleges and their Faculties. "Safe Sedation Practice" Report of an Intercollegiate Working Party chaired by Royal College of Anaesthetists, 2000.

15. A Conscious Decision: Report of an expert group chaired by the Chief Medical and Dental Officer. Department of Health July 2000.

16. Standing Dental Advisory Committee. "Conscious Sedation in the provision of Dental Care”. Report of an Expert Group on Sedation in Dentistry, 2003.

17. Society for Advancement in Dental Anaesthesia (SAAD). Clinical Audit of Conscious Sedation Techniques in Dentistry: A Peer Review, 2001.

18. General Dental Council. “The First Five Years” Undergraduate Dental Curriculum. London. 1997.

19. Robb ND. Sedation in Dentistry. Part 1: Assessment of patients. Dental Update. 1996; May:153-156.

20. Dept of Health, Northern Ireland. Sedation: A survey of General Dental Practitioners. March 2005.

21. Barter C, Renold E. The use of vignettes in qualitative research. Social Research Update 1999; University of Surrey. http://www.soc.surrey.ac.uk/sru/SRU25.html 
22. Bachmann LM, Mühleisen A, Bock A, Riet G, Held U, Kessels AGH. Vignette studies of medical choice and judgement to study caregivers' medical decision behaviour: systematic review. BMC Medical Research Methodology. 2008; 8:50. 
Table 1 Need for sedation with changing levels of anxiety and demand

\begin{tabular}{|c|c|c|c|c|c|}
\hline \multirow[t]{2}{*}{ Anxiety } & \multirow[t]{2}{*}{ Demand } & \multirow[t]{2}{*}{ Mean } & \multirow[t]{2}{*}{ Std. Error } & \multicolumn{2}{|c|}{ 95\% Confidence Interval } \\
\hline & & & & Lower Bound & Upper Bound \\
\hline \multirow[t]{3}{*}{ None } & No & 3.909 & .101 & 3.709 & 4.109 \\
\hline & Yes & 3.596 & .111 & 3.375 & 3.817 \\
\hline & Total & 3.753 & .093 & 3.567 & 3.938 \\
\hline \multirow[t]{3}{*}{ Slightly anxious } & No & 3.758 & .100 & 3.560 & 3.955 \\
\hline & Yes & 3.293 & .102 & 3.091 & 3.495 \\
\hline & Total & 3.525 & .089 & 3.348 & 3.703 \\
\hline \multirow[t]{3}{*}{ Very anxious } & No & 2.737 & .123 & 2.493 & 2.982 \\
\hline & Yes & 2.495 & .125 & 2.246 & 2.744 \\
\hline & Total & 2.616 & .119 & 2.381 & 2.851 \\
\hline
\end{tabular}


Table 2 List of factors influencing choice of sedation with mean rank importance scores

\begin{tabular}{lc}
\hline Factor & Mean rank \\
\hline Anxiety & 2.68 \\
Medical history & 2.72 \\
Chaperone & 3.82 \\
Treatment & 4.18 \\
Training & 4.86 \\
Previous treatment under IV sedation & 5.13 \\
Demand for sedation & 5.26 \\
Age & 5.54 \\
Finance & 7.68 \\
\hline
\end{tabular}




\section{$\underline{\text { Appendix A }}$}

A 32 year old female attends your surgery for removal of a number of periodontally involved upper teeth (754321/123467). She is fit and well, with no contraindication to having IV sedation. Her family and friends normally have dental treatment with sedation and she feels she must have sedation to have the extractions. You perceive the patient to be very anxious about the treatment to be done. 


\section{$\underline{\text { Appendix B }}$}

Influencing factor

Rank order (1 being the most important)

Age

Previous medical history

Type of treatment

Chaperone home post-operatively

Patient's demand for sedation

Finance

Level of postgraduate training in IV sedation

Previous treatment received by patient under sedation

Anxiety level of patient 